\title{
Deinstitutionalisation does not increase imprisonment or homelessness ${ }^{\dagger}$
}

Tatiana Taylor Salisbury and Graham Thornicroft

\section{Summary}

Closing long-stay psychiatric beds remains contentious. The review by Winkler et al in this issue examines 23 studies of deinstitutionalisation for the outcomes of people discharged from psychiatric hospitals after an admission of 1 year or longer. The majority of these studies identified no cases of homelessness, incarceration or suicide after discharge from hospital.

\section{Declaration of interest}

None.

\section{Copyright and usage}

(c) The Royal College of Psychiatrists 2016.
Tatiana Taylor Salisbury (pictured) is Lecturer of Global Mental Health at the Centre for Global Mental Health at King's College London and London school of Hygiene and Tropical Medicine. Graham Thornicroft is Professor of Community Psychiatry at the Centre for Global Mental Health, King's College London.

\section{Defining deinstitutionalisation}

Deinstitutionalisation is generally defined as a shift in the locus of mental healthcare from hospitals to the community, and has been in operation for up to 60 years across many countries worldwide. ${ }^{1}$ Although advocated by both the World Health Organization $(\mathrm{WHO})^{2}$ and the World Psychiatric Association ${ }^{3}$ as an integral step in the development of a modern system for the provision of mental healthcare, this process is not without its detractors.

\section{Concerns about deinstitutionalisation}

Since its introduction in the mid-20th century, critics have claimed a series of adverse effects, most notably increased homelessness and incarceration. Indeed, there has even been a recent call to 'bring back the asylum.' Such reports tend to correlate, in various countries, with the numbers of people who are in psychiatric hospitals and prison, and then suggest that they are causally related. Another argument against deinstitutionalisation is that it is linked to an increase in homelessness for people with mental illness. Indeed, from the early stages of closing psychiatric hospital beds in the USA, commentators expressed concern that where there was insufficient provision of accommodation in the community, homelessness would be the consequence, ${ }^{5}$ although few studies have supported this proposition. ${ }^{6}$

In this issue, Winkler and colleagues systematically review the evidence for any damaging implications of closing long-term psychiatric beds. ${ }^{7}$ They note that much of the evidence used to criticise deinstitutionalisation has 'been based on either ecological studies or, more often, on personal observations or judgements'. To address these limitations, they focused on cohort studies of individuals with severe mental disorders who were discharged from psychiatric hospitals, as a result of deinstitutionalisation, following an admission of 1 year or longer, and where data were analysed at the individual level. Most of the 23 studies included

'See pp. 421-428, this issue. in the review found that at follow-up no cases of homelessness, incarceration or suicide were identified. The authors conclude that, contrary to the results of ecological studies, instances of homelessness, incarceration or suicide among those discharged are rare.

\section{Why investment and implementation matter}

Those people with long-term psychiatric conditions who were included in the studies reviewed were largely discharged to residential facilities in the community with varying levels of support (e.g. to nursing homes, high support facilities, group homes or to semi-independent accommodation). A characteristic shared by all the studies included is that the projects aimed to discharge patients to community settings appropriate to their individual level of need. Ecological studies in this field do not necessarily share this characteristic, and this may be one of the reasons for the discrepancies with the findings of the review by Winkler et al.

In some countries, efforts to deinstitutionalise mental healthcare have been half-hearted, with an emphasis on closing down psychiatric beds rather than on providing comprehensive community-based services. Where bed reduction is done responsibly, either in the context of closing hospitals or 'down-sizing' bed numbers, it has been shown that the overall costs of community care are about the same as for the previous hospital services for such patients. ${ }^{8}$ A systematic review of care for individuals with longer-term mental health problems found evidence of higher quality of life and satisfaction among individuals receiving residential care in the community compared with those in hospital. ${ }^{9}$ On the other hand, where hospital bed closures are seen as a cynical method of making cost savings, without replacement investment in community services, then it is clear that the quantity and quality of care will suffer and may well lead to adverse outcomes for the people concerned.

At the global level there are continuing changes in the provision and use of psychiatric beds across the world. According to the WHO Mental Health Atlas 2014, ${ }^{10}$ there was a slight decrease of $5 \%$ in the number of mental hospitals between 2011 and 2014. A more significant decrease is observed for the number of mental hospital beds, which has dropped by nearly $30 \%$ compared with 2011. The number of beds available in psychiatric wards in general hospitals has shown a marked increase of $60 \%$ between 2011 and 2014. At the same time, despite the global decrease in number of beds, there was an increase of over $20 \%$ 
in rate of admissions to mental hospitals, indicating an increasing bed turnover rate and reducing average length of stay. ${ }^{10}$ In this context, this important review by Winkler et al shows that it is no longer necessary to engage in a stale debate about whether to focus on hospital or community services - rather the debate now needs to address what balance of hospital and community services is needed in low-, middle- and high-income countries.

Tatiana Taylor Salisbury, PhD, Centre for Global Mental Health, Institute of Psychiatry, Psychology and Neuroscience, King's College London, and London Schoo of Hygiene and Tropical Medicine, UK; Graham Thornicroft, PhD, Health Services and Population Research, Institute of Psychiatry, Psychology and Neuroscience, King's College London, UK

Correspondence: Professor Graham Thornicroft, Health Services and Population Research, Institute of Psychiatry, Psychology and Neuroscience, King's College, De Crespigny Park, Denmark Hill, London SE5 8AF, UK. Email: graham.thornicroft@kcl.ac.uk

First received 7 Dec 2015, accepted 8 Dec 2015

\section{Funding}

T.T.S. is supported by the Medical Research council/Department for Internationa Development CHAKA project. G.T. is supported by the National Institute for Health Research (NIHR) Collaboration for Leadership in Applied Health Research and Care South London at King's College London Foundation Trust. The views expressed are those of the author(s) and not necessarily those of the NHS, the NIHR or the Department of Health. G.T. acknowledges financial support from the Department of Health via the National Institute for Health Research (NIHR) Biomedical Research Centre and Dementia Unit awarded to South London and Maudsley NHS Foundation Trust in partnership with King's college London and King's College Hospital NHS Foundation Trust. G.T. is supported by the European Union Seventh Framework Programme (FP7/2007-2013) Emerald project.

\section{References}

1 Thornicroft G, Bebbington P. Deinstitutionalisation - from hospital closure to service development. Br J Psychiatry 1989; 155: 739-53.

2 World Health Organization.The World Health Report 2001. Mental Health New Understanding, New Hope. WHO, 2001.

3 Thornicroft G, Alem A, Antunes Dos Santos R, Barley E, Drake RE, Gregorio G, et al. WPA guidance on steps, obstacles and mistakes to avoid in the implementation of community mental health care. World Psychiatry 2010; 9: 67-77.

4 Sisti DA, Segal AG, Emanuel EJ. Improving long-term psychiatric care: bring back the asylum. JAMA 2015; 313: 243-4.

5 Lamb RH, Bachrach LL. Some perspectives on deinstitutionalization. Psychiatr Serv 2001; 52: 1039-45.

6 Leff J, Thornicroft G, Coxhead N, Crawford C. The TAPS Project. 22: A five-year follow-up of long-stay psychiatric patients discharged to the community. Br J Psychiatry 1994; 165 (suppl 25): 13-7.

7 Winkler $\mathrm{P}$, Barrett $\mathrm{B}$, Mccrone $\mathrm{P}$, Csémy L, Janoušková $\mathrm{M}$, Höschl C. Deinstitutionalised patients, homelessness and imprisonment: systematic review. Br J Psychiatry 2016; 208: 421-8.

8 Knapp M, Beecham J, Anderson J, Dayson D, Leff J, Margolius O, et al The TAPS project. 3: Predicting the community costs of closing psychiatric hospitals. Br J Psychiatry 1990; 157: 661-70.

9 Taylor TL, Killaspy H, Wright C, Turton P, White S, Kallert TW, et al. A systematic review of the international published literature relating to quality of institutional care for people with longer term mental health problems. BMC Psychiatry 2009; 9: 55.

10 World Health Organization. World Mental Health Atlas 2014. WHO, 2014. 